Commonplace • Series 1.3: Global Transition to Open

\title{
The Need for Diversity in Library Funding for OA
}

Demmy Verbeke

Published on: Nov 16, 2021

DOI: $10.21428 / 6 \mathrm{ffd} 8432.19 \mathrm{e} 87593$

License: Creative Commons Attribution 4.0 International License (CC-BY 4.0). 
Collection budgets and acquisition departments of European and North American academic libraries are shaped towards working with legacy publishers. Now that these traditional partners are transitioning towards OA publishing, the easiest path is to redirect money and staff to invest in what these publishers charge for production rather than for the finished product. However, if we do this uncritically, we will end up paying more than before for a system of scholarly communication that is still exclusive (on the side of the authors rather than the readers). We will also contribute to a further monopolization of the market for academic publishing (since the current evolution seems to lead towards a "publisher spendinglockdown") and we will end up "reanointing the commercial oligopolists", whom we blame for the scourges of cost and inaccessibility which currently_plague scholarly_communication. So we need to ask ourselves: is the easiest path the best?

Librarians in research and higher education institutions are entrusted with budgets to invest in a system for scholarly communication that serves the academic community as effectively as possible. If they work at a comprehensive institution, they are also expected to help shape a market that works for a large variety of disciplines, which implies that they need to foster (biblio) diversity and multilingualism. What is more, they are trusted to make ethical choices, favoring democratic approaches and partners who respect human rights (a too often ignored problem in the academic publishing industry.). And as there are numerous indications that the current for-profit model for implementing OA will become even more financially unsustainable than the traditional approach of publishing behind a paywall was, it is plain necessity to develop alternatives if these might save academic institutions money in the middle or long term. Librarians therefore owe it to their profession, and should be supported by the hierarchy of their institutions, to investigate alternatives that lead us in a better direction.

\section{Decisions, Decisions}

Investigating these alternatives by tasking library staff to actively seek out alternative solutions for scholarly communication and by financing publishers, infrastructures, and initiatives that focus on developing these different approaches, comes at a cost. However, that cost is demonstrably smaller than the investment needed to prepare and operate an acceptable read-and-publish deal with a legacy publisher, especially if priority is given to investments that have already been vetted, e.g. by the Global 
Sustainability Coalition for Open Science Services, by the LYRASIS Open Access Community Investment Program, by the Community-led Open Publication

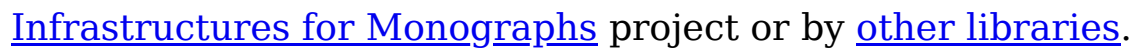

In the end, it also comes down to making managerial choices. People deciding about library budgets can be torn between choosing to invest in a subject specialist focusing on building collections, an IT developer to improve the library system, or a student success librarian focusing on information literacy pedagogy (all valid choices); in the same way they can be torn between an investment in new furniture for the learning center, and an investment in an institutional data repository. Everybody recognizes that they should not exclusively spend all of their budget on one area. Is deciding whether they want their staff to focus exclusively on administering contracts with legacy publishers or to spend some of their time on investigating alternatives so different?

And what about the choice between spending all of the available funds on a single business model for OA versus repurposing some of that budget to try out alternatives? In the choices they make concerning hiring and spending on infrastructure, people higher up within the library hierarchy are tasked to find a balance that works best for the institution-so why would they act differently when making choices on how to spend money on academic publishing, no matter how big or small their budget is?

Ideally, acquisition processes would be shaped to accommodate diversity in spending on academic publishing and spread budget over different suppliers and business models. However, that is currently not the case. One possible counterbalance to the risk of even more monopolization is to safeguard part of the available budget and staff time (again: no matter what the size of the whole is) and designate these to be spent exclusively on non-profit and community-led approaches. This was the reasoning behind the fund for Fair OA, created by KU Leuven Libraries in 2018. In essence, this fund is a separate budget line in the library's budget; just like we have separate budget lines for discipline specific acquisition budget (e.g. law, science\&technology, biomedicine, social sciences, etc.) and a separate budget line for big deals with a handful of major publishers (since these deals incorporate all disciplines and we realized that it would be cumbersome to divide the invoice internally over a multitude of discipline-specific acquisition budgets). The Fair OA fund thus basically mirrors what happened a couple of years earlier to streamline the administration of big deals (namely: creating a separate budget line for them), by setting aside part of the means of the library to be spent exclusively on developing alternatives for the for-profit 
approach to academic publishing and other tools and instruments for scholarly communication. The fund is small-currently $160,000 € /$ year and a staff investment of approximately 0,4 FTE, which is just a fraction of the whole if you consider that $\mathrm{KU}$ Leuven Libraries spends about $11,000,000 € /$ year on collections and has a little more than 173 FTE staff means-but, at least in our opinion, goes a long way. It contributes to the financial sustainability of non-profit approaches and helps to promote the message that we need such alternatives and are willing at KU Leuven to move beyond simply paying lip service to them.

\section{KU Leuven Fund for Fair OA}

The KU Leuven Fund for Fair OA is set up in two parts. The first part is used to help grow Leuven University_Press (LUP). as an OA publisher. LUP was established as a mission-driven university press back in 1971. In line with its values, the press embraced OA early on and is recognized by the European Research Council (ERC) as a trusted OA publisher. Together with the encouragement of Green OA through the institutional repository Lirias (supported by a policy that KU Leuven authors should deposit a copy of their work and by Belgian legislation which enables the dissemination of pre-final versions), LUP has thus, for some years already, played a prominent role in the promotion of OA with a steadily growing portfolio of books published openly.

The business model is centered on author-facing charges, but in order to stimulate OA even more and help authors without access to the necessary funds, we use part of the KU Leuven Fund for Fair OA to finance host-university subsidies for OA books published by_LUP. Depending on the affiliation and access to additional means (such as project funding) of the authors, the fund subsidizes $1 / 3,2 / 3$, or even the whole of the publication costs. This opportunity to secure even partial intervention in the author fees is clearly being noticed, including outside of Leuven. Whereas 13 proposals were approved in 2018 and again in 2019, this number rose to 20 in 2020 (and 10 applications were already approved in the first half of 2021). What is more: 24 out of the 56 applications submitted so far came from authors not affiliated with KU Leuven. In order to promote this part of the fund, a short clip was recently made which explains the application process: 


\section{Visit the web version of this article to view interactive content.}

\section{Publish your book in Open Access with the KU Leuven Fund for Fair OA and Leuven University Press}

The second part of the fund is set up to support a wide array of open scholarship initiatives, on the condition that these are non-profit and community-led. Efforts to secure financial sustainability for these through library membership programs are on the rise, helped by the support of prominent players like LYRASIS and Jisc, but individual libraries might struggle to join these programs if their budget structure and decision-making processes are not geared for this. We found that one of the main advantages of our fair OA fund is that it not only ensures that part of the library's budget is spent on non-profit and community-led initiatives in scholarly communication, but also that it makes the decision-taking process and the administrative handling a lot easier if you have a separate budget line with that exact purpose. Due to a growing awareness of the necessity to include funding for other forms of open infrastructure as well, the name of the fund has quickly become somewhat misleading, as we now consider it more like a fund for responsible open scholarship, still exclusively devoted to non-profit and community-led approaches but not limited to the publication of articles and books in OA.

Investments through the KU Leuven Fund for Fair OA are thus spread over hostuniversity subsidies, Diamond OA programs, subscribe-to-open programs, support for small (mostly scholar-led) OA presses, and collective funding initiatives for open scholarship tools and infrastructure. It might only represent a fraction of what KU Leuven Libraries invests in the ecosystem for scholarly communication, but we believe that it is an important element in our efforts to stimulate more diversity in the market. We hope that we, in our modest way, contribute to promoting and sustaining alternatives for the dominant for-profit solutions and we consider the fund an important step in being able to hit the ground running as more "mission-aligned funding exchange (MAFE)" initiatives-some of which are scheduled to go live in the next couple of months-are realized. 